\section{Commentary: You have to be able to walk the walk if you want to have a successful proximal aortic procedure}

\author{
Ansar Hassan, MD, PhD
}

Frailty has been defined in terms of an accumulation of deficits that results in a loss of physiological reserve. When applied to an elderly population, this concept allows for the differentiation of biological age from chronological age, with biological age serving as a more sensitive predictor of survival. ${ }^{1}$ In recent years, the negative impact of frailty on outcomes following cardiac surgery has become the subject of numerous publications, ${ }^{2,3}$ with cardiac surgeons attempting to find ways to defrail patients in advance of their cardiac procedure. ${ }^{4}$

To date, few studies have examined the effect of frailty in patients undergoing thoracic aortic surgery. Ganapathi and colleagues $^{5}$ used a frailty score composed of 6 elements - age, body mass index, anemia, hypoalbuminemia, history of stroke, and total psoas volume-to identify patients at risk for worse short- and long-term outcomes following thoracic aortic surgery. Gomibuchi and colleagues ${ }^{6}$ used a similar frailty score composed of 7 elements, including the psoas muscle index, to identify patients at risk for late mortality following surgery for acute type A aortic dissection.

In their study presented in this issue of the Journal, Hobbs and colleagues ${ }^{7}$ set out to determine the effect of frailty on postoperative outcomes following proximal aortic surgery using a singular measure: $5-\mathrm{m}$ gait speed. The primary outcome of interest was a composite of

\footnotetext{
From the Department of Cardiac Surgery, New Brunswick Heart Centre, Saint John, New Brunswick, Canada.

Disclosures: The author reported no conflicts of interest.

The Journal policy requires editors and reviewers to disclose conflicts of interest and to decline handling or reviewing manuscripts for which they may have a conflict of interest. The editors and reviewers of this article have no conflicts of interest.

Received for publication April 27, 2020; revisions received April 27, 2020; accepted for publication April 28, 2020; available ahead of print May 15, 2020.

Address for reprints: Ansar Hassan, MD, PhD, Department of Cardiac Surgery, New Brunswick Heart Centre, 400 University Ave, PO Box 2100, Saint John, New Brunswick, Canada, E2L 4L2 (E-mail: ahassan@dal.ca).

J Thorac Cardiovasc Surg 2022;163:898-9

$0022-5223 / \$ 36.00$

Copyright $($ c 2020 by The American Association for Thoracic Surgery

https://doi.org/10.1016/j.jtcvs.2020.04.142
}

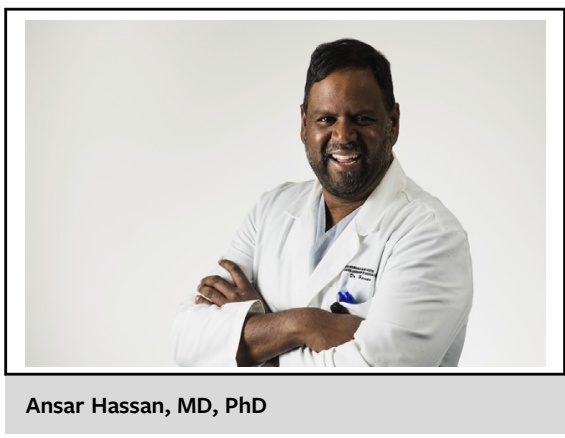

CENTRAL MESSAGE
In patients undergoing proximal
aortic surgery, 5-m gait speed
provides a valuable assessment
of risk and offers an opportunity
for prehabilitation whereby such
risk may be mitigated.

in-hospital mortality, renal failure, prolonged ventilation, and discharge to a location other than home. A cutoff of $0.83 \mathrm{~m} / \mathrm{s}$ was used to separate slow from normal gait speed. Following risk-adjustment, slow gait speed was found to be an independent predictor of worse in-hospital outcomes.

In a continuing effort to better understand the frailty phenotype, this study provides valuable insight into the considerable weight that $5-\mathrm{m}$ gait speed alone has in being able to predict adverse outcomes following proximal aortic surgery. Despite the small sample size, 5-m gait speed testing was associated with a 2.34-fold greater likelihood of experiencing the primary outcome of interest. This was even after adjusting for the EuroScore II risk score, which already includes "poor mobility" as a patient-related factor.

Admittedly, this study has some limitations, the most pronounced of which is a significant number of "eligible" patients who did not undergo 5-m gait speed testing. A comparison of patients who underwent the test with those who did not showed a greater comorbid disease burden in the latter group. The effect of this result on the ultimate study findings is not clear, and as such, the authors' final results should be interpreted with caution.

Having said that, this study is important for 2 reasons. First, it supports the role of prehabilitation in mitigating the risk faced by patients with slow preoperative gait speed. Second, during a global pandemic, when patients are being carefully selected depending on risk factor profiles and their potential burden on hospital resources, the ability to identify 
at-risk patients using a singular and easily obtainable measure is of inestimable value.

\section{References}

1. Mitnitski AB, Graham JE, Mogilner AJ, Rockwood K. Frailty, fitness and late-life mortality in relation to chronological and biological age. BMC Geriatr. 2002;2:1.

2. Yanagawa B, Graham MM, Afilalo J, Hassan A, Arora RC. Frailty as a risk predictor in cardiac surgery: beyond the eyeball test. J Thorac Cardiovasc Surg. 2018; 156:172-6.e2.

3. Sepehri A, Beggs T, Hassan A, Rigatto C, Shaw-Daigle C, Tangri N, et al. The impact of frailty on outcomes after cardiac surgery: a systematic review. J Thorac Cardiovasc Surg. 2014;148:3110-7.
4. Stammers AN, Kehler DS, Afilalo J, Avery LJ, Bagshaw SM, Grocott HP, et al Protocol for the PREHAB study - preoperative rehabilitation for reduction of hospitalization after coronary bypass and valvular surgery: a randomised controlled trial. BMJ Open. 2015;5:e007250.

5. Ganapathi AM, Englum BR, Hanna JM, Schechter MA, Gaca JG, Hurwitz LM, et al. Frailty and risk in proximal aortic surgery. J Thorac Cardiovasc Surg. 2014;147:186-91.e1.

6. Gomibuchi T, Seto T, Komatsu M, Tanaka H, Ichimura H, Yamamoto T, et al Impact of frailty on outcomes in acute type A aortic dissection. Ann Thorac Surg. 2018;106:1349-55.

7. Hobbs RD, Norton EL, Wu X, Willer CJ, Hummell SL, Prager RL, et al. Gait speed is a preoperative indicator of postoperative events after elective proximal aortic surgery. J Thorac Cardiovasc Surg. 2022;163:886-94.e1. 